$1-1-2002$

\title{
An empirical analysis of quality of life and health in selected regions of West Virginia
}

James Bukenya

Follow this and additional works at: https://researchrepository.wvu.edu/ wv_agricultural_and_forestry_experiment_station_bulletins

\section{Digital Commons Citation}

Bukenya, James, "An empirical analysis of quality of life and health in selected regions of West Virginia" (2002). West Virginia Agricultural and Forestry Experiment Station Bulletins. 726.

https://researchrepository.wvu.edu/wv_agricultural_and_forestry_experiment_station_bulletins/616 @ WVU. It has been accepted for inclusion in West Virginia Agricultural and Forestry Experiment Station Bulletins by an authorized administrator of The Research Repository @WVU. For more information, please contact ian.harmon@mail.wvu.edu. 


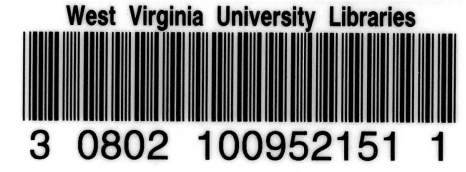

An Empirical

Analysis Of Quality

Of Life And Health

In Selected Regions

Of West Virginia

James Bukenya, Tesfa Gebremedhin,

Denny Smith, and Peter Schaeffer

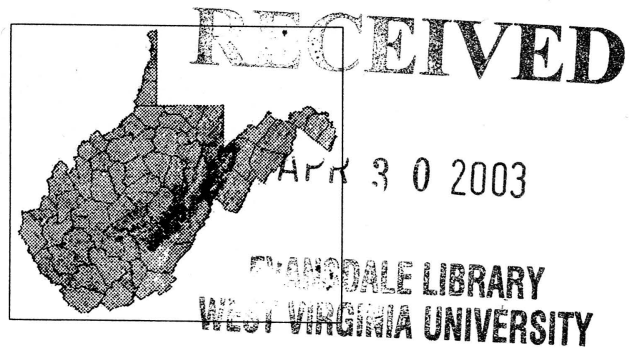

West Virginia Agricultural and Forestry

Experiment Station

Bulletin 726

$S 127$

.E1

726 
West Virginia University is an Equal Opportunity/Affirmative Action Institution. The University does not discriminate on the basis of race, sex, age, disability, veteran status, religion, sexual orientation, color, or national origin in the administration of any of its educational programs or activities, or with respect to admission or employment. Further, faculty, staff, students, and applicants are protected from retaliation for filing complaints or assisting in an investigation under the University's Equal Opportunity/Affirmative Action Plan. Inquiries regarding the University's non-discrimination policy may be directed to the director, Affirmative Action Office/Equal Employment Opportunity Programs, West Virginia University.-Office of the President

West Virginia University is governed by the West Virginia University Board of Governors and the West Virginia Higher Education Policy Commission.

West Virginia Higher Education Policy Commission: J Michael Mullen, Chancellor, Charleston, WV; John R. Hoblitzell, Chair, Charleston, WV; Shawn R. Williams, Vice Chair, Clarksburg, WV; J. Thomas Jones, Secretary, Huntington, WV; Elliott G. Hicks, Esq., Charleston, WV; Ron D. Stollings, M.D., Madison, WV; Kay H. Goodwin, Charleston, WV; David L. Stewart, Charleston, WV; Mary Clare Eros, Esq., Shepherdstown, WV; HEPC Website: http://www.hepc.wvnet.edu/index.html

Board of Governors, West Virginia University: Cathy M. Armstrong, Secretary, Wheeling, WV, Term Expires 2004; Curtis H. (Hank) Barnette, Vice Chair, Bethlehem, PA, Term Expires 2004; Samuel A. Chico, III, Morgantown, WV, Term Expires 2002; Elizabeth E. (Betty) Chilton, Charleston, WV, Term Expires 2003; Dr. Paul Gates, DDS, MBA, Bronx, NY, Term Expires 2004; Terry T. Jones, University Relations Chair, Morgantown, WV, Term Expires 2004; Vaughn L. Kiger, Chair, Morgantown, WV, Term Expires 2005; Douglas J. Leech, Student Affairs Chair, Morgantown, WV, Term Expires 2003; T. Joseph Lopez, Business Affairs Chair, Arlington, VA, Term Expires 2005; Thomas E. Potter, Academic Affairs, Chair, Charleston, WV, Term Expires 2003; Rodney K. Thorn, East Rutherford, NJ, Term Expires 2002; Sandra M. Weese, Middlebourne, WV, Term Expires 2002; Roy S. Nutter, Faculty Senate Chair, Morgantown, WV; Paul R. Martinelli, Classified Staff Rep., Morgantown, WV; Jeremy A. Posey, Student Rep., Morgantown, WV. 


\title{
An Empirical Analysis Of Quality Of Life And Health In Selected Regions Of West Virginia
}

\author{
James Bukenya, Tesfa Gebremedhin, \\ Denny Smith, and Peter Schaeffer
}

\section{Table of Contents}

Abstract ii

Introduction 1

Theoretical Model 2

Estimation Model 3

Data Sources and Definitions $\quad 4$

Figure 1: Study Area $\quad 5$

Table 1: Summary of Variables 7

Survey Data Analysis 8

Table 2: Levels of Quality of Life Satisfaction 9

Empirical Results and Analysis 8

Table 3: Frequencies of Actual and Predicted Outcomes for OrdProbt Model 10

Table 4: Ordered Probit Maximum Likelihood Estimation: Structural Form Equations 15

Table 5: Ordered Probit Maximum Likelihood Estimation: Reduced Form Equation 16

Table 6: Predicted Probabilities 17

$\begin{array}{ll}\text { Summary and Conclusion } & 18\end{array}$

References $\quad 19$

The authors are, respectively, former Graduate Research Assistant, Professor of

Agricultural and Resource Economics, Associate Dean of Academic Affairs and Professor and Director, Division of Resource Management, Davis College of Agriculture, Forestry and Consumer Sciences, West Virginia University. We acknowledge the review comments of Dale Colyer, Alan Collins and Gerard D'Souza.

This research was supported by Hatch funds appropriated to the West Virginia University Agricultural and Forestry Experiment Station. 


\begin{abstract}
This paper examines the relationship between quality of life, health and several socioeconomic variables. The analysis utilizes survey data obtained from a survey questionnaire administered on a random sample of over 2000 residents of West Virginia, and spatial data obtained by geocoding the survey respondents' addressees. The secondary data used were obtained from the Bureau of Business and Economic Research and the Regional Economic Information System. Quality of life is measured by a three-point categorical measure of overall satisfaction and an ordered probit model is used to examine the relationships. The empirical results are consistent with the theoretical predictions and indicate, for instance, that quality of life satisfaction increases with income and education while it decreases with unemployment. Marital status significantly affects satisfaction, with being single having a negative effect on both health and quality of life satisfaction. In addition, there is evidence for gender differences in quality of life among married and unmarried individuals.
\end{abstract}




\section{Introduction}

The concept of quality of life has been the subject of popular and academic studies since the 1930s. During the past decade, however, the number as well as the scope of the studies has increased dramatically (Reichert and Rudzitis, 1992; Clark and Oswald, 1994; Hall and Jones, 1997, 1998; Heubusch, 1998; Easterly, 1999; Dissart and Deller, 2000; Deller et al., 2001). Recent studies have evaluated the quality of life within local jurisdictions, and among nations (Mencken, 1998; Gerdtham, 1997; Sousa-Poza et al., 2000). The methods of analysis range from journalistic approaches to elaborate scientifically based research strategies. Despite the burgeoning literature, there is little unanimity on this subject. The concept has never been defined precisely, and one can rather quickly conclude that the term "quality of life" means whatever the writer of the moment chooses it to mean, especially as the subject is treated in the popular press (Owen and Wayne, 1990). Yet, various units of the government have long engaged in policies designed to influence quality of life in someway or another. This policy-oriented use of the concept has been a key reason for studying quality of life since the early development of social indicator research in the 1960s.

In this paper we examine a composite measure of life satisfaction among lowincome rural residents in West Virginia by assessing the independent and joint effect of a theoretically-based set of exogenous and endogenous variables. The study defines quality of life as the product of the interplay among social, health, economic and environmental conditions which affect human and social development. Utilizing results previously published, the effects of factors that have been found to influence a "satisfied" or "dissatisfied" response to questions about quality of life and health are reinvestigated. This is done in an attempt to reconcile inconsistencies and conflicts in previous quality of life and health studies by controlling for geographical differences within the studied regions through spatial analysis.

Over the last 15 years conceptual models of place well being in sociology have continued to emphasize the importance of regions and geographical space (Lyson and Tolbert, 1996). It has been argued (Anselin, 1988; Anselin and Griffith, 1988; Doreian, 1980; Ord, 1975; Land and Deane, 1992) that when geographical units of analysis are used in regression models, there is a potential for spatial dependence, or spatial autocorrelation. This is particularly true in research with politically constructed geographical units of analysis, such as counties (Land and Deane, 1992; Doreian, 1981; Mencken, 1998). Traditional econometrics, however, has largely ignored these two issues (spatial dependence and spatial autocorrelation) although their presence violates the Gauss-Markov assumptions ${ }^{1}$ (LeSage, 1999).

Previous research findings (Killian and Tolbert, 1993; Carlino and Mills, 1987) have shown, for instance, that there is considerable work-related commuting across county borders, thus supporting the argument that the expansion and contraction of economic

\footnotetext{
1 Gauss-Markov assumes that explanatory variables are fixed in repeated sampling. Spatial dependence violates this assumption (LeSage, 1999) and this gives rise to the need for alternative estimation approaches. Similarly, spatial heterogeneity violates the Gauss-Markov assumption that a single linear relationship exists across the observations.
} 
activity is impervious to politically constructed geographical borders (Anselin, 1988; Land and Deane, 1992). If the dependent variables in the analysis are spatially dependent, spatial lag is present and if not corrected for, the reported regression estimates could be biased. Similarly, if spatial error is present the regression coefficients in the analysis may be inefficient. The presence of either spatial lag or spatial error (or both) could substantially change the conclusions of the analysis. To support this argument, Mencken (1997) reported higher levels of well being in the southern Appalachian counties at the end of the 1980s. However, when he reanalyzed the data while addressing spatial autoregression, the results were significantly different (Mencken, 1998).

This paper advances the literature by developing a spatial modeling approach to enhance the results of life satisfaction studies based on survey data. The study has two major objectives. The first objective is to examine quality of life aspects that are important to and that result from living and working in rural areas. The second objective is to reinvestigate the effects of those factors that have been found in previous studies to facilitate satisfied or dissatisfied responses, and to compare the differences and similarities with previous quality of life and health studies.

\section{Theoretical Model}

Economic theory emphasizes the process by which individuals rationally allocate resources to meet their needs, thereby "producing" utility. Economists characterize the problem of resource allocation in terms of maximizing utility, subject to constraints on the availability and substitutability of resources, and they have developed a general method to model the maximization process (Schuessler and Fisher, 1985). The theory posits that individuals derive utility according to the following function:

$$
U_{i}=U_{i}\left(h_{i}, x_{i}, s_{i}\right)
$$

where, $U_{i}$ represents the utility of individual $i(i=1, \ldots, \mathrm{I}), h_{i}$ is the health status of individual $i, x_{i}$ is a vector of private goods consumed, and $s_{i}$ is a vector of socioeconomic factors that affect utility (Gardtham and Johannesson, 1997; Boadway and Bruce 1984).

Health is produced according to the following health production function:

$$
h_{i}=f\left(m_{i}, h_{0 i}, s_{i}\right) \text {, }
$$

where $m_{i}$ is a vector of health goods such as medical care, and $h_{0 i}$ is the initial (given) health status. Utility is maximized subject to the budget constraint

$$
Y_{i}=P_{x i} x_{i}+P_{m i} m_{i} \text {. }
$$

$Y_{i}$ represents the exogenously given income of individual $i, P_{x i}$ is a vector of private goods prices faced by individual $i$, and $P_{m i}$ is a vector of health goods prices faced by individual $i$. This leads to the following indirect utility function:

$$
V_{i}=V_{i}\left(h_{i}\left(Y_{i}, P_{x i}, P_{m i}, h_{0 i}, S_{i}\right), Y_{i}, P_{x i}, S_{i}\right)
$$

$V_{i}$ represents utility or life satisfaction. The exogenous variables $\left(Y_{i}, P_{x i}, S_{i}\right)$ may influence utility either directly or indirectly through the intervening health variable. This suggests two alternative approaches for estimating the utility model. The first approach is to model the intervening health variable explicitly in the following equation system: 


$$
\begin{aligned}
& V_{i}=\beta_{1}+\beta_{2} Y_{i}+\beta_{3} P_{x i}+\beta_{4} h_{i}+\beta_{5} S_{i}+\varepsilon_{1} \\
& h_{i}=\beta_{6}+\beta_{7} Y_{i}+\beta_{8} P_{x i}+\beta_{9} P_{m i}+\beta_{10} h_{0 i}+\beta_{11} S_{i}+\varepsilon_{2}
\end{aligned}
$$

Alternatively, equation (6) can be substituted for $h_{i}$ in equation (5) and the following reduced form model estimated:

$$
V_{i}=\beta_{12}+\beta_{13} Y_{i}+\beta_{14} P_{x i}+\beta_{15} P_{m i}+\beta_{16} h_{0 i}+\beta_{17} S_{i}+\varepsilon_{3}
$$

In the above models, $\beta_{1}$ through $\beta_{17}$ represents coefficients to be estimated and $\varepsilon_{1}$ through $\varepsilon_{3}$ are error terms, assumed to have a zero mean and constant variance. In the first model we also assume that $\operatorname{cov}\left(\varepsilon_{1}, \varepsilon_{2}\right)=0$. The full structural approach of equations (5) and (6) distinguishes between the indirect effects of the exogenous variables working through health and the direct effects of the exogenous variables, after controlling for health, That is, the model identifies the process underlying the effects of the exogenous variables. The second approach (equation (7)) captures only the total (direct and indirect) effects of the exogenous variables in a reduced form equation. In this paper both approaches are used to evaluate both the direct and indirect effects of the variables.

\section{Estimation Model}

For relationships involving ordinal dependent variables the appropriate techniques are ordered probit or logit models (Hanushek and Jackson, 1977; Amemiya, 1981; Cameron and Trivedi, 1986; Greene, 1993). These techniques take the ceiling and floor effects into account and avoid the use of subjectively chosen scores assigned to the categories. Because the dependent variables are ordered responses, we used an ordered probit model.

Let $V_{i}^{*}$ be a continuous, latent variable representing, for instance, the cardinal utility function of the individual. We assume linear dependence between the latent variable $V_{i}^{*}$ and $X_{i}$, and $\beta$ and $\varepsilon_{i}$ :

$$
V_{i}^{*}=\beta X_{i}+\varepsilon_{i}, \quad \varepsilon_{i} \sim \mathrm{N}\left(0, \sigma^{2}\right),
$$

The variable $V_{i}^{*}$ defines a variable $v_{i}$, related to the above-mentioned categories in the following way:

$$
v_{i}=\left\{\begin{array}{l}
0 \text { if } V_{i}^{*} \leq \theta_{0} \\
1 \text { if } \theta_{0}<V_{i}^{*} \leq \theta_{1} \\
2 \text { if } \theta_{1}<V_{i}^{*}
\end{array}\right.
$$

$\theta_{i}=0,1$, are unobservable thresholds. Denoting the cumulative density function of the standard normal distribution as $\Phi(\cdot)$, it follows that the probabilities of an individual belonging to a given category are:

$$
\begin{aligned}
& \operatorname{Prob}\left[Y_{i}=0\right]=\Phi\left[\mu_{0}-\alpha X\right], \\
& \operatorname{Prob}\left[Y_{i}=1\right]=\Phi\left[\mu_{1}-\alpha X\right]-\Phi\left[\mu_{0}-\alpha X\right], \\
& \operatorname{Prob}\left[Y_{i}=2\right]=1-\Phi\left[\mu_{1}-\alpha X\right],
\end{aligned}
$$


with $\alpha=\beta / \sigma$ and $\theta_{j} / \sigma=0,1$. Note that only the ratios $\beta / \sigma$ and $\theta_{j} / \sigma$ can be estimated (Dustman, 1996). If the regression model contains a constant term, the full set of coefficients is not identified. A common normalization is to set $\mu_{0}=0$, which means that the estimated coefficients $\mu_{i}, i=1$ represent the differences in the respective thresholds: $\mu_{i}=\mu_{i}-\mu_{i-1}$ (Greene, 1995; Dustman, 1996).

To correct for misspecification, a multiplicative heteroscedasticity ordered probit model is used to estimate the structural equations (5) and (6) and the reduced form equation (7). Equations (5) and (6) are recursive (triangular) systems with a diagonal $\sum$ matrix. That is, there is a unidirectional dependency among health and utility, and we assume that the disturbances across equations are contemporaneously uncorrelated (Gardtham and Johannesson, 1997). The equations in the utility-health system are thus estimated separately using the ordered probit model (Greene, 1993; Gardtham and Johannesson, 1997).

\section{Data Sources and Definitions}

Micro level and spatial data are used in this study and these data are drawn from a quality of life survey. The secondary data are obtained from the Bureau of Business and Economic Research at West Virginia University (BBER, 2000), and the Regional Economic Information System (REIS, 1998).

Survey Data - The survey data were obtained from the quality of life mail survey conducted in $2000^{2}$. The survey was sent to 2000 residents in 21 counties located in the southern and Eastern Panhandle regions of West Virginia (Figure 1). The residents were selected randomly using telephone numbers for mailing addresses.

\footnotetext{
: Completed questionnaires were received from 1,060 individuals (return rate 53 percent), of whom 532 were female and 528 were male. In the final examination of the completed survey questionnaires, thirty-two (32) questionnaires were discarded, because the respondent did not answered certain questions that were important to the study, or did not follow the instructions provided in the survey questionnaire. Therefore, the data used in the empirical analysis are based on 1,028 questionnaires (return rate 51.4 percent). The survey was conducted by the authors and was supported by the Hatch funds appropriated to West Virginia University Agriculture and Forestry Experiment Station.
} 


\section{Figure 1: Study Area}

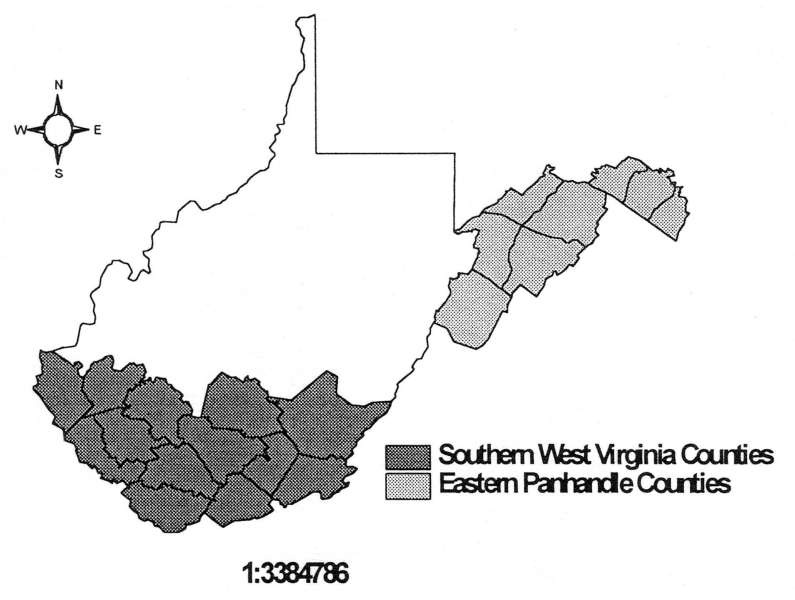

Spatial Data - To generate the spatial data, the regions of analysis were defined as West Virginia counties within the study area. Topological information was generated through the use geographical information systems (GIS). GIS was also used to provide the basic measure of spatial linkages (Fortheringham and Wegener, 2000). To create the spatial weight matrix that describes the linkages, the "address geocoding process" in ArcView 3.2 was used. This process creates a theme based on addresses in a table, using a reference feature theme. The "reference theme" (street theme with address ranges on each street segment) came from a TIGER (Topologically Integrated Geographic Encoding and Referencing) file, and the information was converted to an ARC INFO street coverage with address ranges in its attribute table. The data were obtained from ESRI-ArcData online (ESRI, 2000).

To define the spatial variable, the issue of whether proximity to health services adds to satisfaction was addressed. Economic theory suggests that by virtue of better access, households located closer to a hospital should have a higher health (utility) bundle. Using this argument, a spatial weight matrix was designed based on the location or spatial attributes of the household from the hospital closest to it. Using the geocoded household addresses and hospital locations in the counties, three distance buffers ( 1 mile apart) were designed around the hospitals to measure the potential benefits associated with a household being closer to a hospital. Households that fall within the buffer zones were assigned an adjacency value of one (1); all other households were assigned adjacency values of zero (0). This process yields weight matrixes ${ }^{3}$ that are used to define three spatial dummy variables: SPATIAL1, if a household falls within the one-mile distance buffer around the hospital; SPATIAL2, if a household falls within the two-mile buffer; and SPATIAL3, if the household falls within the three-mile distance buffer around the hospital. The reference category is the one-mile distance buffer (SPATIAL1) 4

\footnotetext{
${ }^{3}$ We use the first-order contiguity matrix (row-standardized so that each row's elements sum to one). We define the prestandardized form of this matrix, WP defined such that $w_{p_{i}}$, is 1 if the $i^{\text {h }}$ and the $f^{\text {th }}$ observation share a common buffer, and 0 otherwise.

4 See Bukenya (2001) for a detailed discussion of the spatial weight matrix.
} 
Many studies, particularly those conducted by psychologists, have used additive indexes of some kind to measure satisfaction (Ellen and Turner, 1997; Vanfossen, 1981; Gove et al., 1983; Sousa-Poza and Sousa-Poza, 2000; Lu, 1999). In compiling these indexes, researchers first determine a list of personal or neighborhood attributes that are deemed important to individuals. Then they ask respondents to rate the attributes on a Likert-type scale, i.e., to express the extent of their agreement or disagreement with statements that reflect positive or negative attitudes toward these attributes. The ratings are then added up to generate an aggregate measure (Clark and Oswald, 1994). Such aggregate measures of satisfaction are deemed unreliable because expressed satisfaction represents integrated participant perceptions that embrace a wide range of external conditions (Golant, 1982; Gerdtham and Johannesson, 1997). Moore (1986) posits that a reacting individual is likely to attach different levels of importance to various attributes of his/her life and their weights are not likely to be well understood. Therefore, it becomes difficult if not impossible to construct externally calculated reliable measures of life satisfaction. To avoid the above-mentioned complication, the dependent variables, as described below and in Table 1, are measured using a single question.

Quality of life satisfaction measurements are obtained by asking a categorical question and rating the responses on a three-point scale. The ranking of the responses provides three levels of satisfaction. Since we assumed the full comparability of utility functions, the satisfaction derived from the three utility levels is taken to be the same for all individuals. Following the same approach, the health index is also represented by a categorical measure (Table 1). This type of categorical health measure has been shown to capture important information about the individual's health (Connelly et al. 1989) and to be an important predictor of mortality (Wannamethee and Shaper, 1991; Kaplan and Camacho, 1983; Idler and Kasl, 1991). The health index variable is also used as an independent variable in the estimation of the structural quality of life equation, by entering two dummy variables for fair health and good health. 


\section{Table 1: Summary of Variables}

\section{Dependent variables}

a.) CATEGORICAL QUALITY OF LIFE SATISFACTION Assessment of personal satisfaction:

$0=$ the daily life is never a source of personal satisfaction,

$1=$ the daily life is sometimes a source of personal satisfaction,

$2=$ the daily life is a source of personal satisfaction most of the time.

b.) CATEGORICAL HEALTH INDEX Assessment of own health on a three-point scale:

$0=$ poor health, 1 = fair health, 2 = good health.

\begin{tabular}{|c|c|}
\hline \multicolumn{2}{|c|}{ 2. Independent variables } \\
\hline MALE & $=1$ if male \\
\hline RACE & $=1$ if white \\
\hline AGE1 & $=1$ if age is $18-34$ years \\
\hline AGE2 & $=1$ if age is $35-44$ years \\
\hline AGE3 & $=1$ if age is $45-64$ years \\
\hline AGE4 & $=1$ if age is $>64$ years \\
\hline UNEMPLOYM & $=1$ if unemployed \\
\hline CIVIL STATUS & $=1$ if the individual is not married or cohabiting \\
\hline HPROBLEMS & $=1$ if the parents or siblings had any health problems \\
\hline EDUC1 & $=1$ if less than high school education \\
\hline EDUC2 & $=1$ if high school education \\
\hline EDUC3 & $=1$ if university education \\
\hline INC1 & $\begin{array}{l}=1 \text { if the gross annual income is in the first quartile of the income } \\
\text { distribution, i.e., }<\$ 20,000\end{array}$ \\
\hline INC2 & $\begin{array}{l}=1 \text { if the gross annual income is in the second quartile of } \\
\text { the income distribution, i.e., } \$ 20,000-\$ 25,353\end{array}$ \\
\hline INC3 & $\begin{aligned}= & 1 \text { if the gross annual income is in the third quartile of the } \\
& \text { income distribution, i.e., } \$ 25,354-\$ 34,075\end{aligned}$ \\
\hline INC4 & $\begin{array}{l}=1 \text { if the gross annual income is in the fourth quartile of } \\
\text { the income distribution, i.e., }>\$ 34,076\end{array}$ \\
\hline RELIGION & $=1$ if religion is said to be a source of strength and comfort \\
\hline AMENITIES & $=1$ if there is a hospital or college/University in the county of residence \\
\hline HEALTHO & $\begin{array}{l}=1 \text { if the health status is rated as bad health in the categorical health } \\
\text { question }\end{array}$ \\
\hline HEALTH1 & $=1$ if the health status is rated as fair in the categorical health question. \\
\hline HEALTH2 & $=1$ if the health status is rated as good in the categorical health question \\
\hline $\begin{array}{l}\text { LOCAL GOVT. } \\
\text { REGION } \\
\text { GOVT. EDUC. EXP }\end{array}$ & $\begin{array}{l}=1 \text { if the performance of the county government is rated as fair or good } \\
=1 \text { if the individual lives in a county located in Southern WV. } \\
=\text { Government expenditure on education and training assistance in } 1998\end{array}$ \\
\hline YEARS OF RESIDE & $=1$ if more than 10 years of residence \\
\hline NEIGHBORHOOD & $=1$ if satisfied with the neighborhood as a place to live \\
\hline ENVIRONMENT & $=1$ if concerned with the quality of the environment in the county \\
\hline SPATIAL EFFECT & $=1$ if the household falls within the designed distance buffers \\
\hline
\end{tabular}




\section{Survey Data Analysis}

Initial examination of the survey responses reveals that a clear majority of the respondents (57 percent) rated their life favorably. The high favorable ratings might be indicative of upward bias. Upward bias in self-reported questionnaires is usually attributed to the tendency individuals have to conform or adapt to their existing environment over time and consequently report a reasonably high level of satisfaction (Amerige and Aragories, 1990; Lu, 1999).

The overall quality of life satisfaction responses are presented in Table 2. Some interesting results are: (i) Individuals in Morgan and Lincoln counties reported the highest levels of quality of life satisfaction whereas individuals in Hardy and Berkeley counties reported the lowest levels of quality of life satisfaction. (ii) The counties with the highest as well as those with the lowest levels of satisfaction are located in the Eastern Panhandle region. Observation (ii) implies that regional differences are not the only possible reason for differing values in the reported satisfaction levels. Perhaps the most interesting observation is not that differences exist among counties but that, in all counties, the level of satisfaction is remarkably high (over 50 percent). Only a minority is clearly dissatisfied.

\section{Empirical Results and Analysis}

The empirical results suggest that the models explain a substantive amount of the variations in the dependent variables. The goodness of fit value (pseudo R-square) is 0.299 and 0.318 in the quality of life and health structural equations, respectively. The goodness of fit value for the reduced form quality of life model is 0.295 . However, the pseudo Rsquare as a measure of goodness of fit deserves only limited attention, because it is chosen to maximize the joint density of the observed dependent variables rather than maximizing a criterion based on prediction of $y$, as with $\mathrm{R}^{2}$ in OLS regression analysis. To further examine the goodness of fit of the estimated equations, frequencies of actual and predicted outcomes are therefore reported in Table 3.

The results in Table 3 suggest that the structural and reduced form equations correctly predict 683 (66 percent) and 684 (67 percent), respectively, of the 1028 observations. The structural form equation predicts that 429 (observed: 383) of the total 1028 respondents fall in the higher satisfaction category. The reduced form equation predicts that 477 (observed: 383) of the total respondents fall in the highest satisfaction category. In general, however, the two models perform similarly (Table 3) with the structural model correctly predicting $66 \%$ of the outcomes and the reduced from model $67 \%$. The results underline the importance of controlling for the respondents' health status in quality of life models. 
Table 2: Levels of Quality of Life Satisfaction

Daily life is a source of

Daily life is never a Daily life is some times satisfaction most of the source of Satisfaction a source of satisfaction time

\begin{tabular}{|c|c|c|c|c|c|}
\hline County & $\begin{array}{l}\% \text { of county } \\
\text { Responses }\end{array}$ & $\%$ of county Responses & $\%$ of county Responses & $\begin{array}{c}\text { Number of } \\
\text { Observations }\end{array}$ & Ranking \\
\hline Morgan* & 5.26 & 15.79 & 78.95 & 30 & 1 \\
\hline Lincoln & 9.09 & 12.12 & 78.79 & 33 & 2 \\
\hline Greenbrier & 7.41 & 14.81 & 77.78 & 46 & 3 \\
\hline Grant $^{*}$ & 12.96 & 22.22 & 64.81 & 54 & 4 \\
\hline Pendleton* & 11.11 & 25.93 & 62.96 & 34 & 5 \\
\hline Wyoming & 5.19 & 32.47 & 62.34 & 58 & 6 \\
\hline McDowell & 9.09 & 28.79 & 62.12 & 66 & 7 \\
\hline Monroe & 11.11 & 26.67 & 62.22 & 45 & 8 \\
\hline Wayne & 5.56 & 33.33 & 61.11 & 36 & 9 \\
\hline Fayette & 11.67 & 28.33 & 60.00 & 60 & 10 \\
\hline Mineral $^{*}$ & 12.77 & 29.79 & 57.45 & 47 & 11 \\
\hline Logan & 13.10 & 29.76 & 57.14 & 27 & 12 \\
\hline Hampshire* & 15.15 & 30.30 & 54.55 & 77 & 13 \\
\hline Raleigh & 7.41 & 38.89 & 53.70 & 54 & 14 \\
\hline Mercer & 20.83 & 27.08 & 52.08 & 48 & 15 \\
\hline Boone & 14.29 & 34.92 & 50.79 & 63 & 16 \\
\hline Summers & 10.00 & 40.00 & 50.00 & 60 & 17 \\
\hline Jefferson ${ }^{*}$ & 17.14 & 34.29 & 48.57 & 35 & 18 \\
\hline Mingo & 8.47 & 44.07 & 47.46 & 59 & 19 \\
\hline Berkeley* & 23.38 & 31.17 & 45.45 & 66 & 20 \\
\hline Hardy $^{*}$ & 13.04 & 47.83 & 39.13 & 30 & 21 \\
\hline Total & 12.08 & 30.85 & 57.08 & 1028 & ستس \\
\hline
\end{tabular}

* Represents Eastern Panhandle Counties 
Table 3: Frequencies of Actual and Predicted Outcomes for OrdProbt Model

Structural Form Quality of Life Equation

\section{Predicted}

\begin{tabular}{lrrrrlrrrr} 
Actual & 0 & 1 & 2 & Total & Actual & 0 & 1 & 2 & Total \\
0 & 346 & 4 & 1 & 351 & 0 & 349 & 1 & 1 & 351 \\
1 & 7 & 98 & 189 & 294 & 1 & 31 & 61 & 202 & 294 \\
2 & 23 & 121 & 239 & 383 & 2 & 66 & 43 & 274 & 383 \\
Total & 376 & 223 & 429 & 1028 & Total & 446 & 105 & 477 & 1028 \\
\multicolumn{2}{l}{ Model Prediction } & & & & & & & &
\end{tabular}

The predicted percentages are calculated as: (predicted/total sample) ${ }^{\star} 100$

To control for heteroscedasticity in the data, the variance of the error terms is assumed to take the form: $\operatorname{Var}\left[\varepsilon_{i}\right]=\left[\exp \left(\gamma z_{i}\right)\right]^{2}$. The variables included in $Z_{i}$ are income and government expenditure. The estimates of the variance functions $s^{5}$ based on the above specification suggest that income and government expenditure significantly explain the variation in the disturbance variances across observations. The estimated effects of each independent variable on the dependent variable are discussed and summarized in Tables 4 and 5. To facilitate the interpretation of the results, the predicted probabilities of being in the highest quality of life satisfaction category for each level of the explanatory variable are also reported in Table 6 at the mean level of all explanatory variables.

Looking at the effects of the demographic variables we see that age, gender, and marital status tend to be associated with both health and quality of life satisfaction. On the other hand, though race appears as a significant factor in influencing an individual's satisfaction or dissatisfaction with life, it does not appear to have a significant affect on a person's health status in the structural models. The race-health results are somewhat surprising. Based on the general US statistics, race (particularly being Black) is negatively correlated with health. However, our findings show a positive relationship. The possible explanation might lie in the fact that the population of West Virginia is overwhelmingly white, such that the effect of the black race is not captured.

The coefficient of the age (AGE4) variable is negative and statistically significant in both equations. This implies that older individuals are less satisfied with their quality of life, and are more likely to be in poor health status than individuals in the youngest age group (18 to 34 years). The impact of age on health is, of course, expected, but the negative effect of age on satisfaction with quality of life, is not equally obvious. The explanation is probably to be found in the observation that the health status of individuals in the higher age group (AGE4) largely influences quality of life satisfaction. When we hold health status constant, the sign of the AGE4 coefficient becomes positive, implying that when controlled

${ }^{5}$ Test of the variance function. 
for health status, individuals in the highest age group are more likely to be satisfied with life compared to individuals in the youngest age group.

The effect of AGE2 (35 to 44 years) and AGE3 (45 to 64 years) is positive, but only the coefficient on AGE3 is significant in the quality of life equation. The overall results suggest a U-shaped relationship between age and quality of life satisfaction, when health status is controlled for. The predicted probability of being satisfied most of the time in the structural equation is 0.59 in the age-group 18 to 34 years, 0.57 in the age-group 35 to 44 years, 0.55 in the 45 to 64 years and 0.60 in the age group over 65 years.

The results of the marital status variable suggest that being single has a negative effect on both health status and quality of life satisfaction. These results conform to the findings of Gove et al., (1993) who found that a strong causal relationship between being married and quality of life. Because of the direct and indirect effects manifested in the structural form equations, the total effect in the reduced form equation is also negative and statistically significant. The predicted probability of being satisfied most of the time is 0.47 for persons who are single and 0.62 for persons who are married or cohabiting. The effect on satisfaction of being single is greater compared to the difference in satisfaction between the highest and the lowest income quartile $(\mathrm{P}<0.05)$ and the difference in satisfaction between men and women $(\mathrm{P}<0.01)$. However, the effect does not differ significantly from the difference in satisfaction between the highest and the lowest education category.

Male gender and white race have a negative and positive effect, respectively, in both quality of life and health equations, though only white race is statistically significant in the structural equation. In the reduced form equation, both variables maintain their signs, but show a reverse in significance. The predicted probability of being satisfied most of the time is 0.55 for men and 0.60 for women whereas it is 0.57 for being of white race and 0.49 for a non-white race in the reduced form quality of life equation.

The estimated coefficients of the income variables (INC2, INC3, and INC4) are positive and statistically significant in all equations. As predicted by economic theory, the results suggest that individuals with higher incomes are more likely to be satisfied with life and to have better health, other things being equal. The predicted probability of being satisfied most of the time increases from 0.53 in the lowest income quartile to 0.61 in the highest income quartile, taking into account the total effect of income. If only the direct effect of income on satisfaction is taken into account, the difference in the predicted probability for a respondent being satisfied most of the time is only two percentage units between the lowest and the highest income quartiles. This indicates that a large part of the effect of income on quality of life satisfaction occurs through the intervening health variable (Bezruchka, 2001)-probably through health expenditures such as health insurance and drug costs (Nixon, 1997).

The results for the education variable are positive, as hypothesized, and highly significant in both the structural and reduced form model. The results are compatible with theory and with societal expectations that higher education attainment is associated with improved socioeconomic status, higher wage rates, better health, all of which lead to better living standards. The predicted probability of being satisfied most of the time increases from 0.55 with less than high school education to 0.67 for university education, based on the total effect in the reduced form model. If only the direct effect on quality of life satisfaction is considered, the probability of being satisfied most of the time would increase 
from 0.57 (less than high school education) to 0.61 (university education). The difference in satisfaction between having a university education and having less than high school education is greater than the difference in satisfaction between men and women, but not significantly different from the difference in satisfaction between the highest and the lowest income quartile.

Unemployment, as previously hypothesized, has a negative and statistically significant correlation with health status and quality of life satisfaction. Similar to income and education, unemployment affects health status and quality of life satisfaction simultaneously. Labor income is the primary source of income for the majority of households. It is determined by the un/employment rates, number of hours worked, labor participation rate, etc. Thus, unemployment results in lower levels of quality of life and health care. The predicted probability of being satisfied most of the time is 0.49 for individuals who are unemployed and 0.58 for employed individuals. The effect of unemployment on satisfaction is not significantly different from the effect of gender or the effect of being single. The effect is also not significantly different from the difference in satisfaction between the highest and the lowest income quartile.

Health status has a significant and positive effect on quality of life satisfaction. Both health dummy variables are significant and the effect of good health (HEALTH2) is significantly higher than the effect of fair health (HEALTH1). The predicted probability of being satisfied most of the time is 0.38 with a bad health status and 0.62 with a good health status. In the reduced form model, the results suggest that improving a person's health status from fair to good health, for instance, would increase the probability of being "satisfied with life most of the time" by 0.18 . The proxy variable for inherited health status, health problems in the family (HPROBLEMS), is significant and negatively related to health status in the structural form equation. In the reduced form equation, initial inherited health has the hypothesized negative relationship on quality of life satisfaction, but not statistically significant. The predicted probability of being satisfied most of the time in the reduced form equation is 0.36 if the parents or siblings had any health problems (HPROBLEMS) and 0.53 in the absence of any health problems (NO HPROBLEMS).

The variable for religion shows a positive impact in the structural model, but the coefficients are significant only in the health equation. In the reduced form model, the total effect of religion on quality of life satisfaction is positive and significant. Historically, religion has been recognized as a powerful factor in promoting good health among individuals (Yinger, 1957) and the whole society (Durkheim, 1976). This presumption has endured in the theoretical literature, at least in part, because, as Ellison (1991) and Idler (1987) have suggested, religion appears to provide a variety of inducements to personal and community well-being, such as enhanced social integration and support. Idler (1987) adds that involvement in religion might also constrain high-risk behavior, such as smoking, drinking and sexual activity outside a stable relationship.

However, not all studies have supported these hypotheses about the religion-health link. A few studies have shown no relationship between the two, especially when such factors as social class and previous health status are controlled for. Some scholars (Singer, 1979) have even argued that religiosity may have deleterious effects on overall health. Alternatively, individuals in poor health may be drawn to religion in an effort to seek comfort and healing, raising the question of causality. Thus, the overall contribution of 
religion to well-being remains a source of controversy. The predicted probability of being satisfied most of the time by someone who is religious is 0.55 in the reduced form equation, while the probability of being satisfied most of the time by someone who is not religious is 0.48 .

The duration variable (i.e., years of residence) is included to examine the effect that living in the county for more than ten years might have on satisfaction. The estimated results do not have the hypothesized positive effect in the structural model and are not statistically insignificant. In the reduced form model, the variable has the hypothesized positive sign though not statistically significant. The influence of the intervening health variable is a possible explanation for the positive sign in the reduced form equation.

An analysis of the policy variables show that government expenditure on education and local government services has a positive, but not significant, effect on health and quality of life satisfaction. The results imply, for instance, that other things being equal, government expenditure on education and training would increase people's satisfaction. Similarly, the local government services variable is not statistically significant. The predicted probability of being satisfied most of the time in the reduced form equation is 0.59 with good local government services and 0.39 with poor local government services.

As hypothesized, the amenity variable has a positive and significant effect in the structural form quality of life model. The amenity variable has a highly significant positive effect in the health equation, suggesting that the presence of amenities in a region can improve one's health status. In the reduced form equation, the intervening positive effect through the health equation increases the total effect of amenities on quality of life satisfaction. The predicted probability of being satisfied most of the time is 0.55 in counties with medical facilities, higher institutions of learning, or closer to metropolitan areas, and 0.51 in counties without such facilities. In the literature, amenities are closely related to the environment, but the results for the environmental variable are contrary to the hypothesized positive sign.

An analysis of the geographical variables indicates that there is evidence to suggest that location and distance play a role in determining whether an individual will report better health status or not. Given the nature of our data, three spatial variables are included to control for spatial dependence that might influence the analysis. The results suggest that the effect of the spatial variable is more pronounced in the health equation. In that equation, the SPATIAL2 variable has a positive and significant effect, and SPATIAL 3 has a highly significant negative effect. This suggests that individuals residing at a distance beyond a three-mile radius from a hospital are more likely to report poor health status people living within a one-mile radius. With regard to quality of life, the results in the reduced form equation show a negative effect for SPATIAL3. The predicted probability of being satisfied most of the time in the reduced form equation decreases from 0.54 with SPATIAL1 to 0.43 and to 0.38 for SPATIAL2 and SPATIAL3, respectively.

An analysis of the region variable indicates that there is weak evidence to suggest that individuals living in the southern region are more likely to be satisfied with life than those living in the Eastern Panhandle region. Although the coefficient for this variable is positive in the structural quality of life model, it is not statistically significant. The coefficient of the regional variable is negative and statistically significant in both the health and reduced form quality of life model. The predicted probability of being satisfied most of the time is 
0.39 for living in the southern region and 0.41 for living in the eastern panhandle. Overall the results suggest that individuals living in the southern region are less likely to be satisfied with life compared to those residing in West Virginia's Eastern Panhandle region.

Lastly, neighborhood appears to play a significant role in enhancing both quality of life satisfaction and health status. In the structural form model, the coefficient for the neighborhood variable is positive and statistically significant. In the reduced form model, the neighborhood variable maintains both a positive sign and the significance level. The predicted probability of being satisfied most of the time is 0.53 with good neighborhood and 0.46 with bad neighborhood. 


\begin{tabular}{|c|c|c|c|c|}
\hline \multicolumn{5}{|c|}{$\begin{array}{l}\text { Table 4: Ordered Probit Maximum Likelihood Estimation: Structural Form } \\
\text { Equations }\end{array}$} \\
\hline & \multicolumn{2}{|c|}{ QOL Equation } & \multicolumn{2}{|c|}{ Health Equation } \\
\hline Variables & Coefficient & t-ratio & Coefficient & t-ratio \\
\hline ONE & $1.984^{* * *}$ & 4.509 & $2.016^{* * *}$ & 3.775 \\
\hline MALE & -0.530 & -1.515 & $-0.281^{*}$ & -1.645 \\
\hline SINGLE & $-0.572^{*}$ & -1.703 & $-1.233^{*}$ & -1.883 \\
\hline UNEMPLOYM & $-0.280 * * *$ & -4.043 & $-0.285^{* * *}$ & -2.892 \\
\hline RELIGION & $1.345^{*}$ & 1.765 & $0.715^{* *}$ & 1.890 \\
\hline AGE2 & 0.058 & 1.245 & $0.457 e-01$ & 0.928 \\
\hline AGE3 & $0.124^{*}$ & 1.761 & $-0.185 \mathrm{e}-02$ & -0.658 \\
\hline AGE4 & $-0.587^{*}$ & -1.722 & $-1.089^{* * *}$ & -2.550 \\
\hline EDUC2 & $0.217^{* *}$ & 2.250 & $0.198^{* *}$ & 2.301 \\
\hline EDUC3 & $1.171^{*}$ & 1.668 & $0.49 \mathrm{e}-02$ * & 1.658 \\
\hline WHITE & $1.496^{* *}$ & 2.102 & 0.026 & 0.149 \\
\hline INC2 & $0.284^{* *}$ & 2.056 & $1.643^{* *}$ & 2.095 \\
\hline INC3 & $0.175^{* *}$ & 2.429 & $0.186^{* * *}$ & 2.533 \\
\hline INC4 & $0.750^{* * *}$ & 6.408 & $0.226^{* *}$ & 1.932 \\
\hline HEALTH1 & $0.197^{* * *}$ & -2.947 & m.... & men \\
\hline HEALTH2 & $0.269^{* * *}$ & 3.824 & $\ldots$ & $\ldots$ \\
\hline HPROBLEMS & w & w. & $-0.211^{* * *}$ & -2.970 \\
\hline DURATION2 & -0.027 & -1.170 & (n) & $m$ \\
\hline LOCAL GOVT. SERVICES & 0.301 & 1.309 & 0.142 & 1.157 \\
\hline ENVIRON. SERVICES & -0.003 & -1.399 & $-0.516^{*}$ & -1.746 \\
\hline REGION & 0.033 & 0.359 & $-0.265^{*}$ & -1.633 \\
\hline NEIGHBORHOOD & $1.334^{*}$ & 1.715 & $0.538^{*}$ & 1.602 \\
\hline AMENITIES & 1.171 & 1.638 & $0.608 \mathrm{e}-04^{* *}$ & 2.053 \\
\hline SPATIAL2 & 0.069 & 0.739 & $1.345^{*}$ & 1.757 \\
\hline SPATIAL3 & -0.046 & -0.598 & $-0.396^{* * *}$ & -2.357 \\
\hline GOVT. EXP. ON EDUC. & 0.016 & 0.279 & $0.181 \mathrm{e}-01$ & 0.991 \\
\hline$\mu_{1}$ & $1.011^{* * *}$ & 19.459 & $1.294^{* * *}$ & 14.335 \\
\hline Interactions completed & 21 & & 22 & \\
\hline Sample size & 1028 & & 1028 & \\
\hline Log-L & -954.8 & & -961 & \\
\hline Model $\chi^{2}$ & 26.02 & & 12.50 & \\
\hline Pseudo R ${ }^{2}$ & 0.299 & & 0.318 & \\
\hline $\mathrm{DF}$ & 1003 & & 1005 & \\
\hline
\end{tabular}




\begin{tabular}{|c|c|c|c|}
\hline Variables & Coefficient & t-ratio & P-value \\
\hline ONE & $2.730^{* * *}$ & 3.823 & 0.0001 \\
\hline MALE & $-0.276^{* * *}$ & -3.149 & 0.0016 \\
\hline SINGLE & $-2.167^{* *}$ & -2.165 & 0.3046 \\
\hline UNEMPLOYM & $-2.099^{* * *}$ & -3.580 & 0.004 \\
\hline RELIGION & $0.619^{* *}$ & 1.924 & 0.0544 \\
\hline AGE2 & -0.307 & -1.341 & 0.1799 \\
\hline AGE3 & $-0.0001^{* *}$ & -1.895 & 0.0581 \\
\hline AGE4 & 0.003 & 1.383 & 0.1666 \\
\hline EDUC2 & $0.334^{* * *}$ & 3.162 & 0.0017 \\
\hline EDUC3 & $1.786^{* * *}$ & 10.537 & 0.0000 \\
\hline WHITE & $7.959 \mathrm{e}-006$ & 0.345 & 0.7303 \\
\hline INC2 & $0.308^{* * *}$ & 3.291 & 0.0010 \\
\hline INC3 & $0.267^{* * *}$ & 3.176 & 0.0015 \\
\hline INC4 & $0.005^{* * *}$ & 2.435 & 0.0149 \\
\hline HPROBLEMS & $-0.769^{* * *}$ & -6.640 & $3.14 \mathrm{e}-011$ \\
\hline DURATION2 & 0.062 & 1.318 & 0.1875 \\
\hline LOCAL GOVT SERV. & 0.124 & 1.504 & 0.1326 \\
\hline ENVIRONMENT SERV. & $-0.658^{* *}$ & -2.024 & 0.0429 \\
\hline REGION & $-0.124^{*}$ & -1.616 & 0.1062 \\
\hline NEIGHBORHOOD & $0.578^{*}$ & 1.698 & 0.0895 \\
\hline AMENITIES & $1.349^{*}$ & 1.775 & 0.0759 \\
\hline SPATIAL2 & 0.058 & 0.905 & 0.3656 \\
\hline SPATIAL 3 & $-0.587^{*}$ & -1.746 & 0.0808 \\
\hline GOVT. EXPENDITURE & 1.132 & 1.612 & 0.1071 \\
\hline$\mu_{1}$ & $4.762^{* * *}$ & 5.259 & $1.45 \mathrm{e}-007$ \\
\hline Interactions completed & 23 & & \\
\hline Sample size & 1028 & & \\
\hline Log-L & -954 & & \\
\hline Model $\chi^{2}$ & 13.7640 & & \\
\hline Pseudo $\mathrm{R}^{2}$ & 0.295 & & \\
\hline DF & 1004 & & \\
\hline
\end{tabular}




\begin{tabular}{|c|c|c|}
\hline \multicolumn{3}{|c|}{ Table 6: Predicted Probabilities } \\
\hline Variable & Direct Effects & Total Effects \\
\hline MALE & 0.51230 & 0.55211 \\
\hline FEMALE & 0.54872 & 0.60145 \\
\hline SINGLE & 0.47199 & 0.01882 \\
\hline MARRIED & 0.62010 & 0.73251 \\
\hline EMPLOYED & 0.52343 & 0.58647 \\
\hline UNEMPLOYED & 0.43550 & 0.49124 \\
\hline RELIGIOUS & 0.53650 & 0.55111 \\
\hline NOT RELIGIOUS & 0.46219 & 0.48540 \\
\hline AGE1 & 0.59178 & 0.55821 \\
\hline AGE2 & 0.57284 & 0.63417 \\
\hline AGE3 & 0.55390 & 0.96011 \\
\hline AGE4 & 0.60309 & 0.63010 \\
\hline EDUC1 & 0.57221 & 0.55415 \\
\hline EDUC2 & 0.51300 & 0.62832 \\
\hline EDUC3 & 0.61071 & 0.67180 \\
\hline WHITE & 0.57960 & 0.57260 \\
\hline NON WHITE & 0.45607 & 0.49113 \\
\hline INC1 & 0.52084 & 0.53199 \\
\hline INC2 & 0.58016 & 0.57879 \\
\hline INC3 & 0.61884 & 0.58871 \\
\hline INC4 & 0.59874 & 0.61343 \\
\hline HPROBLEMS & 0.38112 & 0.36512 \\
\hline NO HPROBLEMS & 0.61414 & 0.52823 \\
\hline HEALTHO & 0.50000 & 0.38365 \\
\hline HEALTH1 & 0.51192 & 0.44145 \\
\hline HEALTH2 & 0.59587 & 0.62234 \\
\hline DURATION1 & 0.55121 & 0.52211 \\
\hline DURATION2 & 0.55079 & 0.54140 \\
\hline LOCAL GOVT. SERVICES=0 & 0.38100 & 0.39430 \\
\hline LOCAL GOVT. SERVICESS & 0.54675 & 0.59390 \\
\hline ENVIRONMENT SERVICES $=0$ & 0.38767 & 0.32861 \\
\hline ENVIRONMENT SERVICES & 0.56501 & 0.48741 \\
\hline SWV REGION & 0.54199 & 0.39784 \\
\hline EPH REGION & 0.55590 & 0.41541 \\
\hline NEIGHBORHOOD=0 & 0.44133 & 0.46933 \\
\hline NEIGHBORHOOD & 0.52084 & 0.53315 \\
\hline AMENITIES $=0$ & 0.04836 & 0.50515 \\
\hline AMENITIES & 0.50107 & 0.55786 \\
\hline SPATIAL1 & 0.54646 & 0.54650 \\
\hline SPATIAL2 & 0.41234 & 0.43711 \\
\hline SPATIAL3 & 0.28987 & 0.38544 \\
\hline GOVORNMENT EXPENDITURE & 0.41317 & 0.49329 \\
\hline
\end{tabular}

Predicted Probabilities of daily life being a source of personal satisfaction most of the time The predicted probabilities are calculated as $F\left(\hat{\beta}^{\prime} X\right)=\hat{F}$ (Green, 1993: p.645). 


\section{Summary and Conclusions}

It is interesting to briefly relate our results to two recent studies (Gerdtham and Johannesson, 1997; Clark and Oswald 1994) that used a methodology similar to ours, but without controlling for spatial dependence. Looking at the similarities, the results in our study conform to the results in these two studies in several areas. First, the two studies also found that unemployment and being single have strong negative effects on quality of life satisfaction (happiness). Second, they also found a U-shaped relationship between age and quality of life satisfaction, with quality of life satisfaction/happiness being lowest for individuals in their mid-thirties (Clark and Oswald, 1994) and in the age-group 45 to 64 years in our study and in Gerdtham and Johannesson (1997).

There are, however, some important differences in the results. For instance, using Swedish macro data, Clark and Oswald (1994) found no systematic relationship between income and quality of life satisfaction/happiness, and they found a negative relationship between education and quality of life satisfaction. As predicted by economic theory, our study (similar to Gerdtham and Johannesson, 1997) found a positive relationship between quality of life and both income and education. Our study indicates that a significant proportion of the effect of income on quality of life satisfaction occurs through the intervention health services. Clark and Oswald (1994) also found that men were happier than women, whereas in our study and in Gerdtham and Johannesson (1997), women were observed to be happier than men. As Gerdtham and Johannesson (1997) have argued, there are many possible explanations for such divergences in the results. The divergences could reflect differences between regions or countries, or they could reflect differences in the samples or measurement of the variables used.

A component that differentiates our study from the rest of the previous studies is that we try to control for spatial dependence. We acknowledge that testing and correcting for spatial dependence in discrete choice models is technically more demanding than addressed in this paper (Smith and LeSage, 2001; Anselin, 2001; Bell and Bockstael, 2000; Fleming, 2002) such that we can not fully attribute the observed differences in the results on correction of spatial dependency. However, by including a spatial variable in our analysis we (1) allow greater insights into the nature and accuracy of the examined data. (2) Provide a more detailed understanding of the nature of relationships and their variation over space. (3) Demonstrate the possible naiveté of conventional approaches to data analysis that often ignores spatial non-stationarity (Fortheringham and Wegener, 2000: 25 . 26).

In sum, the results in this study support the argument that many "non-economic" variables are as important for quality of life satisfaction as income and consumption. The results suggest that socioeconomic variables such as unemployment, health status, gender, marital status, regional differences and education are as important as income in determining one's satisfaction with the life they lead. These findings imply that studies of equity and distribution issues also take into account the distribution of non-economic factors such as education, health status and employment possibilities when assessing the distribution of welfare in society. 


\section{References}

Amemiya, Takeshi. 1981. "Qualitative response model: a survey." Journal of Economic Literature 19, 481-536.

Anselin, L. 2001. "Spatial econometrics," in B. Baltagl (ed), A Companion to Theoretical Econometrics, Oxford: Basil Blackwell, pp. 310-330.

Anselin, L., Griffith, D.A., 1988. "Do spatial effects really matter in regressional analysis?" Papers of the Regional Science Association 65, 11-34.

Anselin, L., 1988. Spatial Econometrics: Methods and Models. Dordrecht, Kluwer.

BBER. 2000. "County data profile." Bureau of Business and Economic Research, West Virginia University. http://www.be.wvu.edu/serve/bureau/online/cdp.htm

Bell, K.P., Bockstael, N.E., 2000. "Applying the generalized moments estimation approach to spatial problems involving microlevel data." The Review of Economics and Statistics 82, 1: 72 -82.

Bezruchka, Stephen (2001). "Health and income equity," International Health Program University of Washington and Health Alliance International. http://depts.washington.edu/eqhlth/index.html.

Boadway, R.W., Bruce, N., 1984. Welfare Economics. Blackwell, Oxford.

Bukenya, J.O., 2001. "An analysis of quality of life, income distribution and rural development in West Virginia." Dissertation: Division of Resource Management, West Virginia University. Morgantown.

Cameron, C., Trivedi, P., 1986. "Econometric models based on count data: comparisons and applications of some estimators and tests," Journal of Econometrics 1, 29-53.

Clark, A.E., Oswald, A.J., 1994. "Unhappiness and unemployment." Economic Journal $104,648-659$.

Cliff, A. D., Ord, J.K., 1973. Spatial Autocorrelation. London, Pion.

Connelly, J.E., Philbrick, J.T., Smith, R., Kaiser, D.L., Wymer, A., 1989. "Health perceptions of primary care patients and the influence on health care utilization." Supplement to Medical Care 27, 99-109.

Dissart, J.C., Deller, S.C., 2000. "Quality of life in the planning literature." Journal of Planning Literature 15, 1: 135--61. 
Doreian, Patrick. 1980. "Linear models with spatially distributed data: Spatial disturbances or spatial effects?" Sociological Methods and Research 9, 29-60.

Doreian, Patrick. 1981. "Estimating linear models with spatially distributed data." In: Leinhardt, S., (Ed.), Sociological Methodology. San Francisco: Jossey-Boss, 359-88.

Durkheim, Emile. 1976. The Elementary Forms of Religious Life. London, George Allen and Unwin.

Dustman, C., 1996. "The social assimilation of immigrants." Journal of Population Economics 9, 37-54.

Easterly, William. 1999. "Life during growth." World Bank.

http:www.worlbank.org/html/prdmg/grthweb/growth_t.htm.

Ellen, I.G., Austin, M.T., 1997. "Does neighborhood matter? Assessing recent evidence." Housing Policy Debate 8, 4: 833-66.

Ellison, C.G., 1991. "Religious involvement and subjective well-being." Journal of Health and Social Behavior 32, 80-99.

ESRI ArcData Online. 2000. "GIS and Mapping software." GIS data on the web. http://www.esri.com/data/online/index.html.

Fleming, M. 2002. "A review of the techniques for estimating spatially dependent discrete choice models." In Anselin and Florax (eds.), Advances in Spatial Econometrics, Forthcoming.

Fortheringham, A.S., Wegener, M., 2000. Spatial Models and GIS: New Potential New Methods. London: Taylor and Francis.

Gerdtham, U., Johannesson, M., 1997. "The relationship between happiness, health and socio-economic factors: Results based on Swedish micro data." Economic and Finance Working Paper No. 207. Stockholm School of Economics. Stockholm Sweden.

Golant, S.M., 1982. "Individual Differences underlying the dwelling satisfaction of the elderly." Journal of Social Issues 38, 121-133.

Gove, W.R., Hughes, M., Style, C.B., 1983. "Does marriage have positive effects on the well-being of the individual?" Journal of Health and Social Behavior 24, 122-131.

Greene, H.W., 1993. Econometric Analysis, Second Edition, Macmillan Publishing Company, New York. 
Greene, H.W., 1995. LIMDEP TM Version 7.0 User's manual. Econometric Software Inc.

Hall, E.R., Jones, C.I., 1997. "Levels of economic activity across Countries." American Economic Review 87, 2: 173-177.

Hall, E.R., Jones, C.I., 1998. "Why do some countries produce so much more output than others?" Stanford University, mimeo.

Hanushek, E.A., Jackson, J.E., 1977. Statistical Methods for Social Scientists. New York: Academic Press.

Heubusch, Kevin. 1998. "Small is beautiful." American Demographics 20, 1: 43 49.

Idler, E.L., 1987. "Religious involvement and the health of the elderly: Some hypotheses and an initial test." Social Forces 66, 226-238.

Idler, E.L., Kasl, S., 1991. "Health perceptions and survival: Do global evaluations of health status really predict mortality?" Journal of Gerontology 46, 555 565.

Kaplan, G.A., Camacho, T., 1983. "Perceived health and mortality: A nine-year follow-up of the human population laboratory cohort." American Journal of Epidemiology $117,292-304$.

Killian, M., Tolbert, C.Jr., 1993. "Mapping social and economic space." In: Singelmann, J., Deseran, F.A., (Eds.), Inequalities in Labor Market Areas. Boulder CO: Westview Press, pp. 69-82.

Land, K., Deane, G., 1992. "On the large-sample estimation of regression models with spatial or network effects terms: A two-stage least squares approach." In: Marsden, P., (Ed.), Sociological Methodology, Cambridge MA, Blackwell, pp. 221 248.

LeSage, James. 1999. "Spatial Econometrics." In: Loveridge, S., (Ed.), The Web Book of Regional Science, Regional Research Institute, West Virginia University. http://www.rri.wvu.edu/regscbooks.htm

Lu, M., 1999. "Determinants of residential satisfaction: Ordered logit vs. regressional models." Growth and Change 30, 2: 264-84.

Lyson, A.T., Tolbert, C.Jr., 1996. "Small manufacturing and civic welfare in the U.S. nonmetropolitan counties: A regional comparison." Environment and Planning 28, 1779-1794.

Mencken, F.C., 1997. "A study of the region: Regional differences in socioeconomic wellbeing in Appalachia." Sociological Focus 30, 79-97. 
Mencken, F.C., 1998. "Persistent differences in well-being between Appalachia subregions." Growth and Change 29, 469-479.

Moore, E., 1986. "Mobility intention and subsequent relocation." Urban Geography 7, 497-514.

Nixon, John. 1997. "Convergence analysis of health care expenditure in the EU countries using two approaches." Center for Review and Dissemination and Department of Economics and Related Studies. UK: University of York.

Owen, F. J. and Wayne, W. A. (1990). "Defining quality of life in North Carolina." Social Science Journal 27, 1: 75-94

Ord, Keith. 1975. "Estimation methods for models of spatial interaction." Journal of the American Statistical Association 70, 120-26.

Reichert, C.V., Rudzitis, G., 1992. "Multinomial logistic models explaining income changes of migrants to high-amenity counties." Review of Regional Studies 22, 1: 25-42.

REIS. 1969-1998. "State and county level variables." Regional Economic Information System. http://fisher.lib.Virginia.EDU/reis/

Schuessler, K.F., Fisher, G.A., 1985. "Quality of life research and sociology." Annual Reviews in Sociology 11, 129--49.

Singer, M.T., 1979. Coming out of the cults. Psychology Today(January), 72--82.

Smith, T. E., and J. P. LaSage. 2001. A bayesian Probit Model with spatial dependences. Manuscript available at http:///www.spatial-econometrics.com.

Sousa-Poza, A., Sousa-Poza, A.A., 2000. "Well-being at work: A cross-national analysis of the levels and determinants of job satisfaction." Journal of Socio-Economics 29, 517-538.

Vanfossen, B.E., 1981. "Sex difference in the mental health effects of spouse support and equity." Journal of Health and Social Behavior 22, 130-143.

Wannamethee, G., Shaper, A.G., 1991. "Self-assessment of health status and mortality in middle-aged British men.” International Journal of Epidemiology 20, 239-245.

Whittle, P., 1954. "On stationary processes in the plane." Biometrika 41, 434-449.

Yinger. J.M., 1957. Religion, Society, and the Individual. Macmillan, New York. 
Notes 
Notes 
Notes 
[Blank Page in Original Bulletin] 

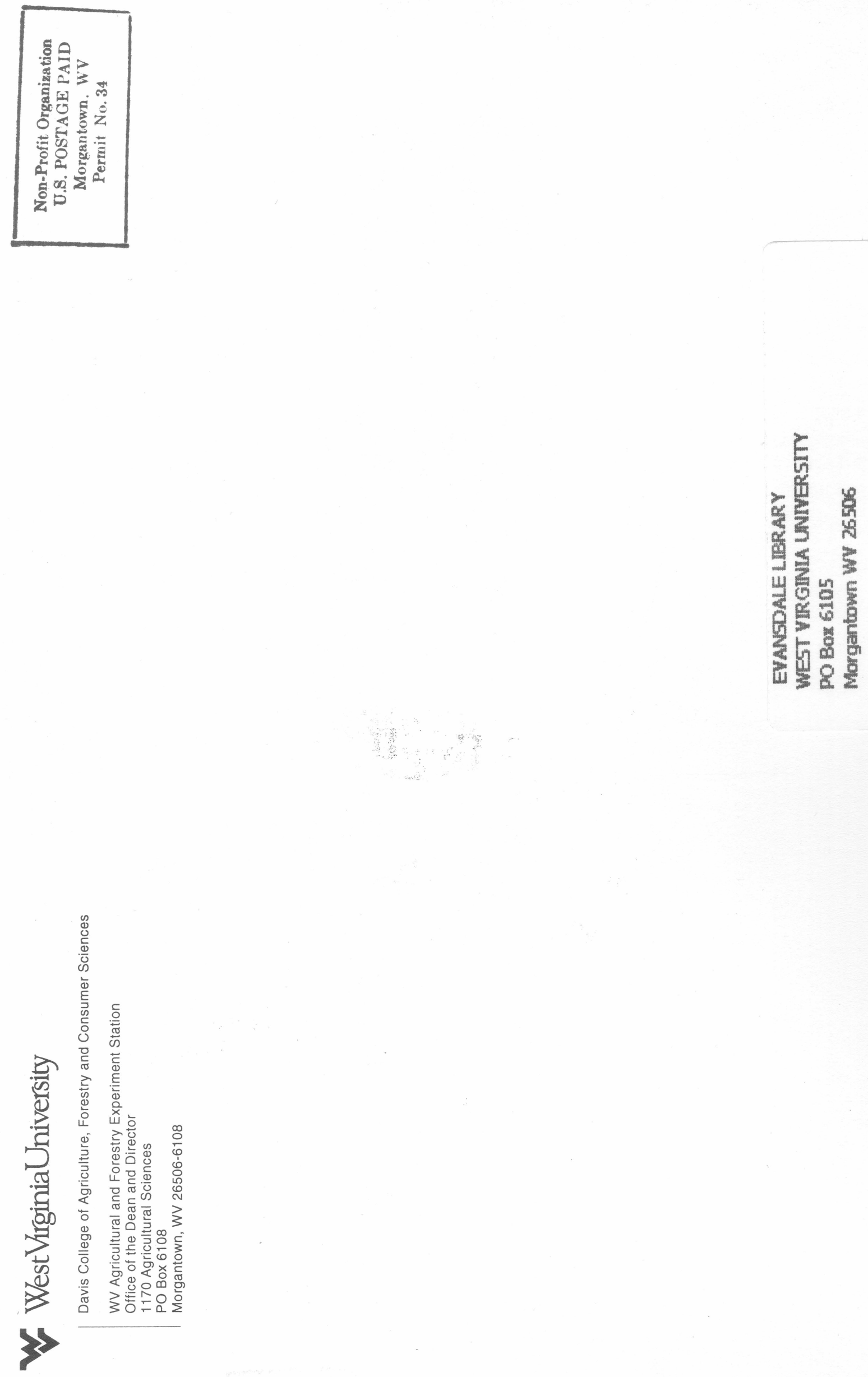
[Blank Page in Original Bulletin] 